\title{
Feminismo de Estado Emergente na Transição Democrática em Portugal na Década de $1970^{*}$
}

\author{
Rosa Monteiro
}

Professora auxiliar do Instituto Superior Miguel Torga e pesquisadora do Centro de Estudos Sociais (CES), da Faculdade de Economia da Universidade de Coimbra (FEUC), Portugal

\section{INTRODUÇão}

m Portugal, o período entre 1970 e 1980 marcou o início e a institu¿ cionalização de políticas públicas promotoras dos direitos das mulheres e da igualdade entre mulheres e homens, e, portanto, da sua representação descritiva e substantiva. É por isso um período cuja análise se revela extremamente importante dado o alcance das transformações legislativas, institucionais, políticas e sociais sobre a situação das mulheres e da igualdade, num contexto global de modernização e democratização. Como venho me referindo em outros trabalhos (Monteiro, 2010a, 2011a), naquela década eliminou-se a discriminação de gênero da legislação, iniciou-se o compromisso internacional com a agenda da igualdade, e criou-se não apenas um, mas dois mecanismos oficiais para a igualdade entre mulheres e homens. Se a produção de um quadro legal e institucional democrático e antidiscriminatório se materializou após 1976, através da nova Constituição, as suas origens encontram-se antes dessa data, em 1970, ainda no período marcelista, naquilo que podem ser consideradas as primeiras manifestações, embora incipientes, do "feminismo institucional" (ibidem).

\footnotetext{
* Este artigo é parte de uma pesquisa mais ampla de doutoramento sobre o fenômeno do feminismo de Estado em Portugal, que se beneficiou do apoio da Fundação para a Ciência e Tecnologia (FCT).
}

DADOS - Revista de Ciências Sociais, Rio de Janeiro, vol. 56, no 4, 2013, pp. 841 a 866. 
A reflexão aqui apresentada explora este quadro de transformações sociopolíticas, centrando-se na criação de um espaço político-institucional para a agenda dos direitos das mulheres (mais tarde igualdade de gênero), especialmente da criação e trabalho do primeiro mecanismo oficial para a igualdade, a atual Comissão para a Cidadania e Igualdade de Género (antes CCF e CIDM, doravante apenas Comissão). Conhecer o contexto de emergência desta ação, suas dinâmicas e constrangimentos, permite-nos compreender a (reduzida) abertura do sistema político português para a integração das questões das mulheres no processo de democratização do país. A reflexão questiona de que forma a democratização incorporou as representantes das mulheres portuguesas e suas reivindicações, como os movimentos de mulheres ${ }^{1}$ e os mecanismos oficiais para a igualdade ${ }^{2}$, mobilizando as propostas analíticas da abordagem do feminismo de Estado explicitada adiante.

Defini como principais fases da evolução do fenômeno em Portugal: 1) feminismo de Estado emergente; 2) feminismo de Estado potenciado; 3) feminismo de Estado formal; e 4) feminismo de Estado desafiado (Monteiro, 2011a). É na primeira fase, ou tipo de feminismo de Estado emergente (1970-1977), que me concentrarei aqui, uma vez que se trata da fase do nascimento e da luta pela institucionalização de um mecanismo oficial, de criação de uma rede de feministas ${ }^{3}$ institucionais e de articulação com redes feministas transnacionais (institucionais, essencialmente), com as organizações de mulheres nacionais e com outros departamentos estatais, na tecitura de constelações cooperativas de mulheres na órbita da Comissão.

\section{OBJETO E MÉTODO}

Pode dizer-se que o compromisso formal do Estado português com as políticas de igualdade começou em 1970, com a criação do Grupo de Trabalho para a Definição de uma Política Nacional Global acerca da Mulher (Monteiro, 2010a e 2011a). Este Grupo, criado no âmbito do Ministério das Corporações e Previdência Social e presidido por Maria de Lourdes Pintasilgo, durante uma ditadura profundamente antifeminista ${ }^{4}$, sobreviveu à Revolução de 1974, ainda que já sob outra designação ${ }^{5}$. Em 1975, a sua presidente, ao tempo Ministra dos Assuntos Sociais, colocou-o em instalação, pelo Decreto-Lei 45/75, dando-lhe o nome de Comissão da Condição Feminina (CCF). Finalmente, em 1977, o primeiro Governo Constitucional pós-revolução, um governo socialista, institucionalizou-a por meio do Decreto-Lei 485/77. A Comissão 
da Condição Feminina passou, em 1991, a chamar-se Comissão para a Igualdade e para os Direitos da Mulher (CIDM), e, desde 2007, Comissão para a Cidadania e Igualdade de Género (CIG) (Decreto-Lei 164/2007, de 3 de maio). Devido à diversidade de designações, refiro-me a este organismo apenas como Comissão. Esta corporifica o fenômeno estudado internacionalmente pela abordagem do feminismo de Estado.

Esta abordagem explora o papel dos mecanismos oficiais em articulação com os movimentos de mulheres na representação descritiva e substantiva das mulheres, consubstanciada na promoção de agendas e reivindicações políticas (Mazur e McBride, 2010). Assume-se que os mecanismos facilitam as representações descritiva e substantiva das mulheres, constituindo-se como potenciais aliados dos movimentos de mulheres para obter acesso à decisão política, contribuindo, assim, para a democracia (Lovenduski, 2005; Mazur e McBride, 2010; McBride e Mazur, 1995).

Inspirada nas teorias do processo político (McAdam, 1998; Tarrow, 1998), a abordagem assume também que, mais do que as características do mecanismo ou dos próprios movimentos de mulheres, são as características do sistema sociopolítico, as estruturas de oportunidades políticas (Tarrow, 1998), como as mudanças de tipos de regime; as reconfigurações do Estado; viragens governativas (esquerda/direita); os focusing events nacionais que geraram discussões públicas (por exemplo, julgamentos de mulheres nas questões do aborto) e internacionais (como exemplo, a Década das Mulheres da ONU e suas Conferências Mundiais) que condicionam o sucesso e efetividade do feminismo de Estado (McBride e Mazur 1995; Mazur e McBride, 2010).

Partindo deste conjunto de pressupostos e instrumentos analítico-concetuais procuro, aqui, responder a algumas questões centrais. Em primeiro lugar, perceber os motivos de um surgimento considerado precoce de mecanismo oficial para igualdade num contexto sociopolítico conservador e antifeminista (1970-1974). Em seguida, questionam-se os fatores que conduziram a este desfecho, especialmente as estruturas de oportunidades políticas e as estratégias facilitadoras. Finalmente, exploro as dificuldades de integração da agenda da igualdade no processo de democratização em curso após a Revolução de 1974.

A pesquisa empírica foi realizada com base num estudo de caso sobre a Comissão, numa abordagem qualitativa composta pela realização de 
53 entrevistas semiestruturadas (técnicos/as e ex-técnicos/as da Comissão; ex-presidentes e dirigentes da Comissão; responsáveis político/as pela tutela; peritas; dirigentes de associações de mulheres; especialistas) e pela análise de material de arquivo (atas e documentos diversos) de legislação, publicações e artigos de imprensa. Os dados foram organizados e analisados com recurso ao software NVivo8. Da análise de conteúdo categorial resultou uma árvore de categorias e subcategorias que permitiu responder às perguntas de pesquisa.

\section{A CRIAÇÃO E INSTITUCIONALIZAÇÃO DA COMISSÃO: CONQUISTA DE ESPAÇO INSTITUCIONAL PARA O FEMINISMO DE ESTADO}

A criação, em Portugal, de uma instituição estatal para a igualdade no período em análise revela algumas peculiaridades:

- Ao contrário do sugerido pela literatura, o feminismo de Estado (McBride e Mazur, 1995), não resultou do apelo ou pressão internos dos movimentos feministas (de segunda onda), que eram proibidos pela ditadura, nem apenas dos processos de modernização e democratização.

- Aconteceu precocemente, logo no início da década de 1970, relativamente a outros países da Europa do Sul (como, por exemplo, Espanha e Itália), onde mecanismos representativos do feminismo de Estado surgiram em meados da década de 1980, cerca de uma década mais tarde (Guadagnini, 1995; Valiente, 1995).

- Parece atípico e insólito o nascimento de um mecanismo de Estado para a promoção da situação das mulheres (ainda que sob a forma de grupo de trabalho) num regime político de ditadura, ainda que em incipiente liberalização, antifeminista, que associava o feminismo ao desmoronamento da arquitetura moral e social, e onde as questões das mulheres eram completamente marginalizadas pela primazia dada à proteção dos valores da família e do estatuto convencional da mulher como esposa e mãe (Gorjão, 2002; Pimentel, 2001; Rêgo, 2010).

O pano de fundo em que nasceu em Portugal um mecanismo representativo do feminismo institucional era profundamente discriminatório. As normatividades legal e social relegavam as mulheres portuguesas a um quadro severo de discriminação (Gorjão, 2002; Monteiro, 2010b; Pimentel, 2001; Rêgo, 2010). Segundo a Constituição Política do Estado Novo (Rêgo, 2010) a mulher, com base na "natureza" e na defesa do 
"bem comum", não podia exercer certas profissões, necessitava de autorização do marido para celebrar contratos de trabalho, não podia realizar trabalho noturno; as convenções coletivas de trabalho perpetuavam a discriminação salarial; no Direito da Família, a mulher era completamente inferiorizada face à figura do "chefe de família", ao "poder marital" e ao dever do "governo doméstico". Enfim, podemos dizer que, quer a legislação, quer a normatividade, as práticas sociais eram profundamente familialistas, conservadoras e patriarcais mesmo na reta final da ditadura, no momento em que as elites marcelistas quiseram implementar uma estratégia de modernização econômica e de abertura ao internacional.

Neste contexto, em 1970, o Ministério das Corporações e da Previdência Social, nomeadamente o Fundo de Desenvolvimento da Mão-de-Obra e o Centro de Estudos, foi o embrião de dinâmicas transformadoras que, ainda que não suficientes, abriram brechas no sistema e permitiram a entrada da temática da promoção dos direitos das mulheres.

\section{Genealogia Breve}

A criação do Grupo de Trabalho foi uma decisão do então Secretário de Estado do Trabalho, Joaquim da Silva Pinto, que decidiu convidar para a sua chefia a engenheira Maria de Lourdes Pintasilgo. O mesmo daria a ela - ligada aos círculos católicos progressistas, única mulher na Câmara Corporativa e figura central do $\mathrm{GRAAL}^{6}$-, a liberdade de convidar pessoas para o Grupo, no interior ou fora daquele Ministério. A incumbência do Grupo seria a de produzir uma Regulamentação do Trabalho Feminino, ligada à formulação do Plano de Fomento, que deveria ter a forma de um Decreto-Lei a aprovar em Conselho de Ministros. O trabalho devia ser realizado em um ano, findo o qual o Grupo se dissolveria.

Aproveitando a experiência internacional, apoiados em textos de organizações especializadas e, acima de tudo, olhando a realidade da sociedade portuguesa que quer contar com a participação consciente, responsável e adulta das mulheres, julga-se chegado o momento de, a partir dos serviços já existentes e das experiências acumuladas, constituir junto do Gabinete do Secretário de Estado do Trabalho e da Previdência, um grupo de trabalho visando a definição de uma política nacional relativa às condições necessárias para a contribuição das mulheres 
para o progresso global do desenvolvimento do país. (Despacho de 13 de maio de 1970)

O Grupo nascia em nome da promoção da "participação da mulher na economia do país" e não explicitamente para a promoção da sua emancipação, àquela altura ideia não tolerada pelo sistema. A contribuição do trabalho das mulheres para as economias e sociedades era a pedra de toque que facilitava e legitimava a necessidade da Regulamentação do Trabalho Feminino e daquele Grupo de Trabalho num contexto legislativo e institucional profunda e explicitamente discriminatório para as mulheres.

Aquele Ministério personificava bem os tempos contraditórios que se viviam no regime do Estado Novo, durante o período marcelista (1968-1974) $)^{7}$, especialmente o confronto entre os blocos político-administrativos mais conservadores e as brisas renovadoras trazidas por uma nova elite de quadros dirigentes, com formação técnica e científica, com experiências internacionais, e grande parte deles ligados a movimentos progressistas católicos, que entraram para o aparelho de Estado nos meados e finais dos anos 1960. Era uma elite que acreditava na promessa renovadora de Marcelo Caetano, sendo alguns, aliás, muito próximos do presidente do Conselho e do seu filho. Fazer parte da Juventude Universitária Católica (JUC) era também um dos mais destacados traços comuns entre a maioria deles. Os contatos internacionais (estágios, entre outros), o estudo da legislação trabalhista de outros países e a realização de estudos sobre a realidade nacional eram já práticas correntes neste Ministério, que se constituía assim como embrião de mudanças marcantes.

Os setores mais progressistas do Ministério das Corporações, para além dos desejos reformistas, confrontavam-se com questões prementes, como era o caso do crescimento da participação das mulheres portuguesas no mercado de trabalho; do aumento dos pedidos de informação de agências internacionais, que chegavam via Ministério dos Negócios Estrangeiros; das condenações que instituições como a Organização Internacional do Trabalho (OIT) faziam ao sistema corporativo português e aos atrasos em matéria de legislação do trabalho.

Maria de Lourdes Pintasilgo viu na criação deste Grupo uma brecha no sistema para a integração mais global das questões das mulheres no desenvolvimento (Monteiro, 2010b). Portanto, a ideia era não centrar o foco da "questão feminina" nas questões do trabalho e do emprego das 
mulheres, mas produzir uma reflexão e revisões legislativas transversais a todas as áreas governativas.

Em reuniões semanais, algumas das quais ocorriam no Gabinete do Ministro, Maria de Lourdes Pintasilgo distribuía trabalhos às técnicas do Grupo ${ }^{8}$. Paralelamente, procurava obter influências, particularmente junto ao Ministro, Baltazar Rebelo de Sousa ${ }^{9}$, no sentido de obter mais meios e de transformar o Grupo numa Comissão, tal como era recomendado internacionalmente, posicionada na convergência entre as forças internacionais e o governo português.

A estruturação de uma proposta de Comissão como um projeto de Decreto-Lei e anexos em que se expunham os resultados dos estudos realizados (Direito da Família, tradução de Convenções e diretivas internacionais, Remunerações...), foi apresentada num extenso relatório, e o Secretário de Estado aprovou a criação de um Grupo de Trabalho para a Participação das Mulheres na Vida Económica e Social (Despacho de 1ㅇ de maio de 1971), cuja designação parecia ir mais de encontro à tendência de conceitualização da questão pelas Nações Unidas.

A discussão das propostas do Grupo, da Regulamentação do Trabalho Feminino, era feita em longas reuniões envolvendo todos os diretores-gerais do Ministério, o que gerava entre os setores mais conservadores e os mais modernizantes acirrados confrontos, muitos deles entre as técnicas e os críticos do seu trabalho, que o acusavam de ser "demasiado ambicioso para a época", "[conter] um tom reivindicativo e discriminatório", "protecionista", "irrealista e inexequível", "[acarretar] encargos para as empresas que elas não podem suportar". Mas o desmontar dessas críticas e os apoios às propostas do Grupo eram também muito significativos da parte de diretores-gerais como João Moura, Nascimento Rodrigues, Acácio Catarino, Elídio das Neves e o próprio Secretário de Estado, Joaquim da Silva Pinto, que numa das reuniões, e face aos argumentos contra a "discriminação positiva" contida na proposta, afirmou não aceitar que "esta seja uma lei que entra a pedir desculpa, que é transitória” (Doc. Arquivo Digital MLP: 0016.038).

Do trabalho realizado apenas foi materializada uma proposta que resultou na publicação da Portaria nํ183/73, de 13 de março, sobre o trabalho condicionado, que proibiu o emprego das mulheres em certas atividades consideradas perigosas em virtude da função genética. As restantes foram "ficando na gaveta". Mas uma conquista foi, sem dúvida, a criação, em 27 de setembro de 1973, de uma Comissão para a Polí- 
tica Social Relativa à Mulher (Decreto-Lei 482/73), na dependência direta do ministro.

Em abril de 1974 o trabalho e a vida da Comissão foram interceptados pela Revolução, e com ela, decididamente, algumas oportunidades se abririam não só à Comissão, mas às mulheres portuguesas em geral. Maria de Lourdes Pintasilgo passou a ocupar a pasta de secretária de Estado dos Assuntos Sociais e depois de ministra dos Assuntos Sociais, cargos que acumulava com a presidência da Comissão que, simultaneamente, tutelava (Decreto-Lei 203/74, de 15 de maio). Em janeiro de 1975, a anterior Comissão foi substituída pela Comissão da Condição Feminina, colocada em regime de instalação pela ministra Pintasilgo (Decreto-Lei 47/75, de 1ㅇde fevereiro). No ano anterior cresceram as solicitações de trabalho internacional, com a preparação do Ano Internacional das Mulheres da ONU e sua Conferência (no México), bem como a análise do projeto de Convenção (Convenção sobre a Eliminação de Todas as Formas de Discriminação contra a Mulher CEDAW). Este contexto internacional favorável, em conjunção com o momento de mudança interno, criaram algumas estruturas de oportunidades ao grupo que, no entanto, se viu forçado a pugnar pela sua consolidação na estrutura político-administrativa do Estado. Digamos que nas aventuras da revolução a Comissão estava esquecida, o que, se não favorecia a sua capacidade, também não a ameaçava de extinção.

Os constrangimentos da Comissão eram diversos, mas dentre os mais marcantes destacavam-se a instabilidades política e governativa dos seis governos provisórios, a mudança de titulares da pasta dos Assuntos Sociais, as tentativas de instrumentalização ou de apagamento da Comissão quando da campanha eleitoral ${ }^{10}$ nas eleições, as reduções do orçamento, a precariedade e atipicidade do seu estatuto jurídico e suas consequências (arrendamento das instalações, direitos sobre viatura ou sobre mobiliário e equipamento), a precariedade da situação contratual das pessoas que ali trabalhavam, o reduzido quadro de pessoal face à envergadura do plano de atividades traçado (Monteiro, 2010a), o fechamento do sistema político à integração de algumas propostas da Comissão, como no caso da Constituinte.

Entre finais de 1975 e inícios de 1976 as técnicas da Comissão fizeram vários contatos políticos com o primeiro-ministro, até que, ainda no VI Governo Provisório, conseguiram ver nomeada uma Comissão insta- 
ladora, presidida pela antiga técnica, Maria do Carmo Romão, para criar a Comissão.

O primeiro governo constitucional, o governo socialista liderado por Mário Soares, materializou a tão aguardada institucionalização, com a publicação do Decreto-Lei 485/77, de 17 de novembro. O apoio incondicional do ministro de Estado, Henrique de Barros, apontado nas entrevistas como o principal aliado nesta altura, e o fato de estar prevista no Programa do Governo (que recusava a criação da tal Secretaria de Estado), tornaram esta institucionalização possível.

Um dos aspetos mais interessantes da criação deste mecanismo oficial para a igualdade é que desde muito cedo ele ofereceu um espaço formal de articulação com as associações de mulheres e com representantes dos diversos setores do governo, através do seu Conselho Consultivo (CC), composto de duas seções: a Seção das ONGs e a Seção Interministerial. O trabalho com os movimentos de mulheres surgira, em 1974, do contato de uma organização que solicitara participar na preparação do Ano Internacional da Mulher. Num cenário marcado por fortes clivagens e lutas político-partidárias, as técnicas da Comissão decidiram estender a representação a outros departamentos de mulheres de partidos existentes, de forma a equilibrar as forças em presença. Outras associações foram se juntando na preparação do Plano de Ação Comum para o Ano Internacional da Mulher, e para a delegação portuguesa à Conferência do México. No levantamento realizado de todas as organizações apenas se identificaram três associações de mulheres: o Movimento Democrático de Mulheres (MDM), o Movimento de Libertação das Mulheres (MLM) e a União das Mulheres Trabalhadoras de Portugal (UMTP), núcleos femininos dos partidos políticos, sindicatos com predominância de mão de obra feminina, associações cívicas (como o Graal, a Associação de Planejamento Familiar, o Ninho) e Associações de Moradores. Foi um trabalho informal, mas bastante articulado e intenso, que viria a dar origem a uma relação institucionalizada com as organizações de mulheres cuja voz era vista como importante no trabalho de pressão da Comissão sobre o governo. Foi o primeiro momento em que a Comissão foi um veículo de acesso ao Estado, e, portanto, uma aliada dos movimentos de mulheres.

A Comissão constituía assim um núcleo duro de trabalho feminista dentro do Estado. O calor revolucionário não deixava espaço, porém, para a participação das mulheres na política, e muito menos para ma- 
nifestações feministas. O trabalho institucional, legitimado pelas exigências internacionais, parecia ser o único meio de ação das mulheres naquele período. A Comissão, através do seu Conselho de ONG, solidarizou-se com as mulheres do MLM, atacadas e injuriadas numa Manifestação no Parque Eduardo VII (atas de reunião do CC de 5 de fevereiro e de 19 de janeiro, de 1975). Longe das ruas, a Comissão procurava expandir redes de apoio e contatos, trabalhando com representantes de outros ministérios e departamentos, na solidificação da Seção Interministerial. Os nascentes movimentos de mulheres encontraram na Comissão o espaço de acolhimento e "militância"; mais do que relações de desconfiança e animosidade, como aconteceu na vizinha Espanha, o caminho que anteviram foi o de uma cooperação necessária determinando-se, desta forma, uma relação simbiótica. A participação no Conselho Consultivo da Comissão compôs uma institucionalização política dos movimentos portugueses de mulheres.

\section{A Importante Contribuição da Comissão}

Assim nascia formalmente o primeiro mecanismo oficial de mulheres e igualdade em Portugal, passados sete anos de existência. Como grupo de estudo, os seus trabalhos eram muito centrados no conhecimento da situação da mulher na legislação portuguesa e a situação da mulher no mundo do trabalho, mais precisamente, na análise das remunerações, onde se "descascava" a legislação nacional, se estudava a realidade, ou seja, a diferenciação salarial por sexo, por sexo e região, por setor, bem como as suas causas; e onde, com base na legislação de outros países e nas recomendações e convenções internacionais, se discutiam possíveis alterações em âmbito nacional. Era a aplicação da Convenção no 100 da OIT ${ }^{11}$ (ratificada por Portugal), e o artigo 119 do Tratado de Roma na legislação portuguesa, relativos à igualdade remuneratória entre mulheres e homens; era a análise do conceito de autoridade familiar no Código Civil; era a análise de remunerações; era a resposta ao pedido da ONU sobre "proteção e integração da mãe solteira", entre outras. Estas técnicas faziam, desta forma, a "tradução" de normas internacionais decisivas, procurando com elas convencer os agentes políticos da necessidade de reformas internas.

Foram anos de dificuldades e atrasos, mas também de alguns sucessos que não se podem menosprezar. Por modestos que tenham parecido face às dificuldades formais e políticas enfrentadas até à sua institucionalização, o fato é que a Comissão produziu, nesse período, um con- 
junto notável de resultados, e que em alguns casos indicam mesmo a capacidade que ela teve (que construiu, que reivindicou através do lobbying) de se integrar no processo de produção de políticas. Exemplo disto é o processo de inclusão de uma técnica da Comissão na Comissão de Revisão do Código Civil, que tinha como missão a elaboração do novo Código de Direito da Família. Outro resultado do trabalho da Comissão foi a publicação do Decreto-Lei 112/76, de 7 de fevereiro, que concedeu pela primeira vez às mulheres trabalhadoras o direito a uma licença maternidade de 90 dias sem interrupção de recebimento de salário. Também, entre 1975 e 1976, a Comissão pôs em funcionamento dois serviços voltados para o exterior (Gabinete de Atendimento e Serviço de Documentação). O trabalho no domínio da regulamentação do trabalho feminino esteve na origem da Lei da Igualdade de 1979 (Decreto-Lei 392/79, de 20 de setembro), que viria a criar a Comissão para a Igualdade no Trabalho e no Emprego (Monteiro, 2010b).

Considero, por isso, este período como sendo já de feminismo de Estado, apesar de apenas em 1977 ter sido institucionalizado o mecanismo estatal, com estrutura orgânica e recursos humanos e financeiros atribuídos. Baseio-me na conceção de McBride e Mazur (1995:5) segundo a qual a classificação de feminismo de Estado não se reduz à mera existência formal de mecanismos oficiais para a igualdade (o que pode não passar de um formalismo), mas implica a sua atividade ou trabalho concreto e substantivo para produzir mudança. Ora, em Portugal nesta altura, ainda que com fragilidades institucionais e um estatuto pouco robusto, os primeiros Grupos de Trabalho e a Comissão em instalação realizaram um importantíssimo trabalho de análise da situação discriminatória das mulheres portuguesas, e de elaboração de arrojadas e "inconformistas" propostas políticas. Como referi acima, ela foi também nesta altura uma importante janela de acesso ao Estado por parte das associações de mulheres já existentes, que participaram na preparação, por exemplo, do Plano de Ação Comum para o Ano Internacional da Mulher. Estas primeiras formas de feminismo de Estado estudaram e confrontaram os decisores políticos com práticas e soluções políticas de outros países, bem como com as recomendações das mais relevantes organizações internacionais na matéria e sua adequação à legislação nacional (Monteiro, 2010a). Simultaneamente, mantiveram e foram reforçando o espaço institucional para a sua própria sobrevivência e expansão enquanto mecanismos de representação e promoção do estatuto das mulheres num contexto de democratização (Monteiro, 2010a). 
Desde o início, e de forma intensificada a partir de 1974, estes mecanismos constituíram-se como pontos focais da promoção de políticas públicas de igualdade entre os sexos, num contexto político adverso, e na ausência de fortes movimentos de mulheres independentes. A Comissão cumpriu, desde o primeiro momento, a missão de representação descritiva e substantiva das mulheres, em duas das três formas apontadas pela literatura sobre feminismo de Estado (McBride e Mazur, 1995; Mazur e McBride, 2010; Mazur 2005):

- Integraram os interesses das mulheres e as questões da igualdade entre os sexos na produção e implementação política;

- Aumentaram a participação das mulheres no Estado, pelo fato de integrarem mais mulheres como funcionárias e darem acesso aos movimentos de mulheres.

Apenas não cumpriram plenamente a terceira condição - facilitar às representantes dos movimentos de mulheres o acesso às esferas do poder - na sua fase inicial, correspondente ao período anterior ao 25 de abril de 1974, um período ainda ditatorial, misógino, onde não existiam polos de militância social feminista ou em nome dos direitos das mulheres.

\section{FATORES DETERMINANTES DE UM NASCIMENTO ATÍPICO E PRECOCE}

Como vimos, ainda que lentamente durante os sete anos (1970-1977), e apesar das dificuldades, as técnicas e a presidente daquele grupo conseguiram singrar no sistema político e institucional e finalmente obter do Estado uma resposta dupla ${ }^{12}$ com a institucionalização da Comissão. Conseguiram ser insiders no processo, participando tanto no resultado formal obtido, como determinando, elas próprias, os termos ou conteúdo da forma institucional criada, conferindo-lhe inclusivamente traços inovadores.

Procurei, na pesquisa, explorar os fatores que promoveram este resultado. Sintetizo-os aqui de forma breve, uns decorrentes do contexto sociopolítico, outros das características da própria Comissão:

1) Estruturas de oportunidades políticas moderadamente abertas, representadas pelo ambiente reformador que se vivia no Ministério das Corporações e Previdência Social, num contexto político globalmente fechado. Como causas da abertura deste subsistema durante o marcelismo podemos destacar: a sua constituição por elites reformadoras, 
partilhando concepções modernizadoras em "tradução" das influências e requisitos internacionais sobre o sistema; a partilha, por essas elites, de uma pertença a grupos de católicos progressistas que reforçavam as suas ligações, também pessoais e informais, ao presidente do Conselho e as protegiam da censura conservadora; a intensificação da pressão internacional para que Portugal atualizasse a sua legislação trabalhista e do trabalho feminino ${ }^{13}$ e varresse o sistema corporativo que legitimava as reformas, bem como o reconhecimento das mulheres como fonte de mão de obra e de contribuição para o desenvolvimento econômico dos países.

- Aceitação interna das mulheres envolvidas, mulheres de elites com capital social e político significativo. O perfil das mulheres envolvidas neste processo e primeiras representantes do feminismo institucional em Portugal foi decisivo. As relações pessoais, a pertença a círculos católicos progressistas entrelaçaram-se, naquele contexto, na fundação de relações institucionais. Estas relações, umas informais outras formais, porque profissionais e baseadas no aporte técnico de cada uma das técnicas, concederam ao grupo fundador algum espaço de acesso ao poder num regime fechado. Neste tipo de contexto altamente fechado, as mulheres de elites são as que têm possibilidade de acesso ao poder, e por essa via, de representar de alguma forma os interesses das restantes, ainda que se possa questionar que grupos de mulheres e como as representarão (Htun e Weldon, 2007). Recordemos que Maria de Lourdes Pintasilgo era presidente do Graal e convidou para o Grupo mulheres também ligadas a essa organização e ao seu círculo. Era um círculo elitista, de mulheres de um grupo social privilegiado, ligado aos meios políticos e católicos reformistas - como uma entrevistada me disse, não eram, de fato, "umas mulheres quaisquer" (entrevista 34). Maria de Lourdes Pintasilgo era uma mulher com proximidade ao poder, com voz, pois, para além da sua militância em grupos católicos de mulheres (Graal), era Procuradora da Câmara Corporativa. A excelência das suas relações políticas e sociais, com base no seu pertencimento à JUC, foi referida como elemento facilitador nas entrevistas que realizei.

Ah, fomos tomar chá [com o Ministro Baltazar Rebelo de Sousa e sua esposa]. A senhora era católica, mas muito progressista. Era assistente social, ela tinha umas experiências de trabalho de mulheres quando era nova. Tinha sentido na pele os problemas da compatibilização. E então ela gostava imenso deste Grupo e do nosso trabalho. Um dia a ML: "ai a 
Dona (já não me lembro do nome] gostaria imenso de nos conhecer" e, então, convidou-nos para ir tomar chá com ela no hotel Lutécia, ou Roma [...]. E eu fui e outra que não me lembro. [...] É a mulher do MINISTRO, era muito entusiasta, com aquela energia e interessava-se imenso pelo nosso Grupo e naturalmente influenciava o marido. (Entrevista 33, ex-técnica da Comissão)

Fazer parte dessas elites sociais e católicas facilitou o recrutamento e a aceitação do trabalho que realizavam num contexto antifeminista:

\begin{abstract}
Sim, era da JUC, sim senhor era da JUC, o Miguel Caetano também teria sido com certeza, era filho do Marcelo. Portanto, há aqui um conjunto de conhecimento pessoal e de confiança pessoal e depois a Maria de Lourdes Pintasilgo tinha todo o Fórum internacional do Graal. Sim, sim, desde sempre do Graal. [...], há aqui de fato um papel da Juventude Universitária Católica, e nessa altura na JUC era o movimento progressista da universidade e, portanto, também um movimento associativo, [...]. Nós conhecíamos todos destes meios e isso ajudava, é claro. Éramos aceitos porque éramos do mesmo grupo, do mesmo meio, disso não tenho dúvidas. Também não havia espaço para mais nada, nessa altura. Das Três Marias ${ }^{14}$ pouca gente sabia, aquilo era uma coisa isolada e amarfanhada pelo Regime, que não tinham a possibilidade de falar em nome das mulheres portuguesas. Nós é que tentamos fazer isso nos trabalhos que fazíamos. (Entrevista 15, ex-técnica da Comissão)
\end{abstract}

2) Importância da pressão internacional ou do "regime Global para a igualdade de mulheres e homens" (Kardam e Acuner, 2003), num período de grande vulnerabilidade interna à pressão internacional que se intensificou (da parte da ONU) desde os anos 1960, com a emissão de pedidos de informação e ação aos Estados membros. Portugal respondia assim ao Programa de Longo Prazo para o Progresso das Mulheres lançado, em 1968, e ao apelo da mesma organização para a criação de comissões nacionais de promoção da condição da mulher. As ligações com a ONU eram intensas e crispadas, devido ao problema colonial. A própria Maria de Lourdes Pintasilgo enfrentou a severidade das críticas na Assembleia Geral da ONU, em 1971, quando discursou sobre os direitos dos povos à autodeterminação e sobre a condição feminina. A incorporação das recomendações e propostas da ONU relativamente à promoção da condição feminina pode ter sido, assim, um preço relativamente baixo a pagar por alguma melhoria da má imagem que o país mantinha junto a esta instituição, justificando parcialmente a abertura 
do governo às questões da condição feminina. Depois da Revolução, a atenção internacional sobre o país reforçou-se ainda mais.

Como Jelena Subotic (2005) defende, a criação de instituições é uma das formas privilegiadas de adoção das normas internacionais pelos países, já que traduz um tipo mínimo de compromisso, servindo muitas vezes até de lip service. Segundo a autora, alguns Estados valorizam a criação destas instituições como estratégia para resolver problemas políticos, sem que isso signifique uma aposta na funcionalidade e efetividade dessas instituições. No caso português, muitas entrevistadas consideraram que a criação e existência daqueles Grupos e, depois, da Comissão, foi apenas tolerada pelos responsáveis políticos, que entendiam que ela seria inócua e controlável, e que era uma forma de ter "ali qualquer coisa para responder lá fora, e para não dar má imagem" (entrevista 7), sem grandes impactos internos: "As pessoas ligadas ao regime achavam que estávamos ali entretidas, naquilo: 'não fazem mal nenhum porque aquilo nunca sai nada'" (entrevista 33). Mas as técnicas daqueles Grupos de Trabalho assumiam-se como "empreendedoras" das recomendações internacionais, numa espécie de concretização portuguesa do designado efeito boomerang (Keck e Sikkink, 1998) nas políticas globais de igualdade entre os sexos, naquele período.

No período de transição democrática, serão também a necessidade de reciclar a imagem negativa do passado e de reforçar a legitimidade como membro respeitável da sociedade internacional, combinadas com as dinâmicas do Ano Internacional da Mulher (1975), que irão motivar a criação da Comissão da Condição Feminina (CCF), em vias de instalação. Na Conferência do México (1975), Portugal chegou mesmo a copatrocinar, com o Peru, a proposta de criação de comissões de mulheres.

Foram estas as razões do contexto ou ambiente político que facilitaram a emergência dos Grupos de Trabalho. Por elas, Portugal foi surpreendentemente precoce, na cena internacional, na criação deste tipo de estruturas. Na Austrália e no Canadá, e na sequência de reivindicações dos movimentos de mulheres, eles nasceram apenas em 1974 e 1971, respetivamente. Na Grã-Bretanha, nasceram em 1975 e na Holanda em 1978. Portugal esteve, portanto, entre os primeiros, antecipando-se mesmo aos seus colegas da Europa do Sul.

3) A iniciativa, atitude e estratégia das primeiras feministas institucionais. Não obstante a importância da relativa abertura do sistema políti- 
co, o fato é que tal como na França foram a pressão e a persistência das técnicas que conquistaram o upgrade de Grupo de Trabalho para uma Comissão. Foi o seu intenso trabalho de lobbying que contribuiu decisivamente para esse resultado, isto porque a vontade política sempre parece ter sido a de "cumprir os mínimos", mesmo num período de renovação democrática, legislativa e institucional depois do 25 de abril de 1974. Como me disse uma entrevistada, ex-técnica dos primeiros Grupos de Trabalho, elas operaram "uma revolução antes do tempo" (entrevista 15). A sua utopia, irreverência e inconformismo, não obstante o reduzidíssimo sucesso das suas propostas legislativas, granjearamlhes como principal vitória a sobrevivência da própria Comissão:

[...] era uma utopia perfeita. Era como se estivéssemos a trabalhar para nada. Mas ao mesmo tempo a Maria de Lourdes dizia "não queremos saber disso para nada. Vamos fazer como se fosse para avançar". E eu disse assim... "mas essas propostas nunca verão a luz do dia". E ela disse assim "vamos ignorar isso, vamos trabalhar como se pudessem... nunca se sabe o que pode acontecer". (Entrevista 33, ex-técnica da Comissão)

- A utilização de estratégias aceitáveis, nomeadamente a não utilização de um discurso feminista nem de direitos das mulheres logo em 1970, que não teria sido tolerado dentro do Ministério e pelo sistema político declaradamente antifeminista. Depois da revolução a mesma cautela discursiva foi mantida, até pelo sinal das reações violentas à manifestação do feminismo radical no Parque Eduardo VII, em 1975.

- A estratégia de lobbying que as técnicas desenvolveram, mesmo depois do afastamento de Maria de Lourdes Pintasilgo, no sentido de institucionalizar a Comissão, usando estratégias informais, contatos diretos com os primeiros-ministros:

[...] e não só lembretes! Fazíamos mesmo reuniões. Eu lembro-me... eu estive em algumas. Olhe, por exemplo, com o Pinheiro de Azevedo, primeiro-ministro. Fomos dizer que era importante, as Nações Unidas...; estava eu, a Aurora, e de ele dizer "sim senhora, as senhoras têm razão. Isso é realmente necessário! Crie-se a Comissão. Então e se é uma Comissão, como é que... se vai ser uma Comissão, tem de ter uma pessoa a presidir, tem de ter uma comissária!" [...] Havia uma preocupação de contato direto, e havia uma abertura. Batia-se à porta deste e daquele. Não é como hoje; hoje se a gente quiser ir falar diretamente, não consegue. Mas naquela altura era muito mais fácil. Os canais eram muito 
mais abertos, estava tudo em revolução (risos). (Ex-técnica e presidente da Comissão)

\section{A REVOLUÇÃO, MUDANÇA DE SISTEMA POLÍTICO, ESTRUTURAS DE OPORTUNIDADES POUCO ABERTAS AO FEMINISMO DE ESTADO}

A revolução de 1974 foi menos amiga das mulheres portuguesas do que se poderia esperar e do que, certamente, muitas delas esperavam. Mesmo num período de renovação democrática, legislativa e institucional como o do 25 de abril de 1974, a vontade política de apenas "cumprir os mínimos" se manteve. Apesar de a discriminação inscrita na própria lei ter se tornado intolerável, não foi facultado espaço político às mulheres e às suas reivindicações e representantes. O seu potencial enquanto estruturas de oportunidades políticas foi, assim, bastante mais limitado do que processos desta natureza podem fazer antever. Democratizou-se o regime político, criaram-se novas instituições democráticas, (re)surgiram os partidos, alterou-se a legislação, abriu-se o país ao exterior, conquistou-se liberdade, mas o balanço feito pelas representantes das mulheres portuguesas nesta altura não foi animador. A democratização foi um processo bem mais lento, demorado e complexo do que a mera extinção do regime autoritário de direita (Gunther, 2002).

Faço, também eu, uma análise relativizadora da contribuição da Revolução portuguesa para o feminismo de Estado, com base na análise da legislação produzida e de documentos da época, da situação da Comissão naquela altura e nos balanços feitos nas entrevistas que realizei. Outros especialistas o fazem também quando analisam a sociedade e o sistema político produzidos pelos processos de transição e consolidação da democracia portuguesa, notando que a continuidade foi mais predominante do que a transformação (Ferreira, 1993; Santos, 1984). Segundo essas análises, um conjunto de legados pré-revolução continuaram a definir e condicionar as relações Estado-sociedade civil em Portugal (Aguiar, 1987; Santos, 1984, 1993). Esses trabalhos têm associado a sociedade e o sistema político portugueses a um modelo oligárquico, dominado por elites, uma sociedade dualista e elitista, dominada por um centro político, com uma sociedade civil frágil, incipiente, e pela incapacidade de os movimentos sociais representarem os grupos sociais (Aguiar, 1987; Teixeira, 2009); um país onde a participação é inexistente ou muito limitada à concentração de poder por elites (onde se destacam as partidárias) e elementos que estas cooptam para os sistemas político e burocrático (Aguiar, 1987; Santos, 1993). 
Assim aconteceu durante a transição democrática, sendo exemplo disso a inclusão da igualdade de gênero na Constituinte. A igualdade das mulheres na Constituição de 1976 foi inscrita sem a participação delas, num resultado que designei de apropriaçã $0^{15}$. Nela, a Comissão foi marginal(izada), a Assembleia da República foi o espaço da sua produção, mas um espaço apenas aberto às elites dos partidos e da Revolução. Os partidos instituíram-se como força hegemônica e ocuparam todo o espaço de mobilização social, esgotando e integrando outros movimentos e forças de contestação social, menosprezando a ligação com as bases e grupos sociais (Aguiar, 1987; Jalali, 2007). Diversos estudos têm falado nesta ocupação do espaço político pós-revoluções por parte dos partidos políticos, o que impede, limita e coopta a expressão dos movimentos sociais. Foi o caso do Chile, onde as relações entre partidos emergentes e movimentos sociais foram mais competitivas do que cooperativas (Waylen, 1997; 1998). Em Portugal esta situação foi diagnosticada, por exemplo, por Daniel Melo (2007) e Virgínia Ferreira (2011). Melo falou de uma "partidocracia" enfraquecedora da sociedade civil (2007: 225); já Ferreira (2011) falou-nos de um espaço público elitista em disputa, onde as questões das mulheres tiveram de rivalizar com as agendas prioritárias dos partidos.

A igualdade produzida pela Revolução foi uma igualdade formal, sem a voz das mulheres, por isso uma igualdade armadilhada (Ferreira, 2011), não assimilada pelo conjunto da sociedade e com muito reduzida possibilidade de se tornar efetiva. Como refere Virgínia Ferreira (ibidem: 40), citando uma ativista, "a lei chegou primeiro do que a emancipação".

A presidente da Comissão - Maria de Lourdes Pintasilgo - manifestava, em 1975, o seu desapontamento com a subalternização das mulheres pela Revolução e denunciava a exclusão e invisibilidade das mulheres portuguesas no processo revolucionário e mesmo a frustração dos sonhos revolucionários (Monteiro, 2010a). Apesar das diversas tentativas ${ }^{16}$ que descrevi exaustivamente nas estratégias para participação na Constituinte (Monteiro, 2011a), e para que as questões das mulheres fossem assumidas com relevância no processo revolucionário (Monteiro, 2010a), a Comissão não conseguiu se inserir nas políticas produzidas na transição democrática, as questões das mulheres não incluíram a agenda do processo revolucionário, e dada a instabilidade política ${ }^{17}$, a Comissão foi gravitando instavelmente na órbita do Ministério dos Assuntos Sociais. Em 1974-75, a Comissão não participou de nenhuma das quatro alterações legislativas produzidas com 
impacto na situação das mulheres. A questão da emancipação e liberdade das mulheres, para além do "direito à não-discriminação", não pareciam encontrar lugar nos quadros interpretativos dominantes, monopolizados pela democracia e cidadania (neutra), sendo mesmo risíveis nas discussões políticas. Face à falta de atenção e de espaço para as suas reivindicações e anseios, as técnicas da Comissão desenvolviam estratégias intensas, designadamente a estratégia de lobby junto aos responsáveis políticos, e a criação de redes transnacionais e do trabalho internacional.

Mais uma vez, depois da Revolução democratizante, foi este intenso trabalho de lobbying das técnicas da Comissão que contribuiu decisivamente para a consolidação institucional de um espaço estatal e político para a representação das mulheres portuguesas e para o feminismo de Estado, num Estado que atravessava um período de paralisia, como comenta Boaventura de Sousa Santos (1984). Por isto defendo que também nesta fase o feminismo de Estado não foi um espaço político oferecido pela Revolução, mas sim conquistado pelas feministas institucionais e suas redes. Esta conquista teve na coincidência entre fatores internos e externos (Ano Internacional da Mulher, Conferência do México e lançamento da Década das Mulheres da ONU), os seus pontos de alavancagem, mas os sucessos da Comissão devem-se, em grande parte, à persistente pressão das suas técnicas:

Nós apanhamos a "crista da onda" dos desenvolvimentos internacionais, que coincidiram com o ambiente mais aberto em Portugal. E 75 foi um ano de grandes mudanças. Houve uma convergência de circunstâncias favoráveis. E estávamos em processo revolucionário. Tínhamos de responder para ficar bem na fotografia, e porque nos beneficiamos, naquela altura do percurso, de outros países. Mas mesmo assim tivemos muito trabalho, sempre, sempre, sempre a lembrar que existíamos e a apresentar trabalho. (Entrevista 22, técnica da Comissão)

A Conferência do México deu-nos força e alento para trabalharmos aqui no país. A partir dela nada voltou a ser igual. Trouxemos ideias, documentação, argumentos, exemplos. Para prepará-la trabalhamos com as ONGs, levamos as ONGs conosco, já viu o pioneirismo?! Aqui dentro não ligavam para nós, mas nós não largávamos o osso (risos). (Entrevista 17, técnica da Comissão)

\section{CONSIDERAÇÕES FINAIS}

Como resulta da análise exposta, a década de 1970 foi marcante no domínio da promoção dos direitos das mulheres e das políticas públicas 
de igualdade, tendo a criação da Comissão sido o epicentro de dinâmicas transformadoras. O espaço existente no sistema político-institucional português para este feminismo de Estado emergente foi um espaço conquistado, diria mesmo perseverante e arduamente conquistado, por estas redes mais ou menos institucionalizadas de mulheres (políticas, funcionárias públicas, representantes de organizações de mulheres) face à indiferença e até animosidade de uma sociedade civil pouco sensível ou reivindicativa nestas questões relativas ao estatuto das mulheres, e à indiferença do instável poder político, mesmo num momento revolucionário e democratizante como foi a década de $1970^{18}$.

O momento de renovação e democratização legislativa em que ocorreram, e que legitimava uma intervenção legislativa antidiscriminatória, à que acresceu o profundo dinamismo internacional nestas matérias, suscitado, por exemplo, pela celebração da Década das Mulheres da ONU, criaram estruturas de oportunidades políticas moderadamente abertas às representantes das mulheres. A instabilidade política associada às dinâmicas do processo revolucionário se, por um lado, impediram um ritmo mais acelerado de transformações, por outro, proporcionaram quadros interpretativos mobilizáveis e criaram um espaço ou margem de manobra para a Comissão (ainda pré-institucionalizada), que funcionava numa brecha do processo revolucionário e da luta dos partidos políticos pelo poder. Este quadro de renovação legislativa foi um episódio de transformação do Estado português aproveitado pelas representantes das mulheres na Comissão, de forma estratégica e proativa. A ação de lobbying da Comissão, suas técnicas e redes ou constelações cooperativas de mulheres, usando um conceito de Holli (2008), teve condutibilidade e eficácia num sistema elitista e clientelista como é o sistema político português.

O contexto modernizador e democratizante não foi, por si só, suficiente para a entrada das questões da igualdade de gênero, juntando Portugal a outros países onde as fases de transição democrática não foram $f o-$ cusing events decisivos para as representantes das mulheres (Ferreira, 2011; Franceschet, 2003). O espaço político para as mulheres teve, por isso, de ser conquistado. Talvez por este motivo a Comissão se sentisse e fosse sentida como um "corpo subversivo" no Estado, como "contracorrente", como muitas pessoas referiam nas entrevistas. O sentido de militância e proatividade, o sentido de coesão em torno de uma causa, a importância da constituição desta rede de "militantes oficiais" com 
proveniências e elos comuns, como muitas delas se autodesignaram nas entrevistas, foi um fator de sucesso decisivo neste contexto.

Podemos, por isso, concluir desde já que a Comissão funcionou neste contexto como verdadeira representante substantiva e descritiva das mulheres portuguesas, tendo sido não só uma inside agitator ou militante dentro do Estado, mas também uma aglutinadora das fracas energias da sociedade civil, num contexto que, não obstante estar em transformação democratizante, foi apenas moderadamente aberto à agenda política dos direitos das mulheres e da igualdade.

(Recebido para publicação em janeiro de 2013)

(Reapresentado em junho de 2013)

(Aprovado para publicação em setembro de 2013) 


\section{Rosa Monteiro}

\section{NOTAS}

1. Adota-se a definição proposta por McBride e Mazur (2008:226) de que "um movimento de mulheres significa ação coletiva por mulheres, organizadas explicitamente como mulheres, apresentando reivindicações na vida pública baseadas nas identidades sexualizadas das mulheres". Esta definição não prescreve táticas disruptivas ou não convencionais como critério exclusivo para a definição de movimento.

2. Segue-se a definição de Mazur e McBride (2010:29) de "women's policy agency" como um corpo governamental formalmente estabelecido; encarregado da promoção do estatuto das mulheres e da promoção da igualdade de mulheres e homens.

3. Segui, no estudo, a concetualização de McBride e Mazur (2005:11) que permite classificar de ação e discurso feminista aquele que se "identifica com as mulheres, é explicitamente sexualizado, representa as mulheres, visa melhorar o estatuto das mulheres e desafia as hierarquias sociais de sexo".

4. Este antifeminismo ficou bem expresso na extinção de associações feministas, na legislação discriminatória e da associação do feminismo ao desmoronamento dos "valores da família" e do estatuto convencional da mulher como esposa e mãe (Gorjão, 2002; Pimentel, 2001; Rêgo, 2010). Investigadoras como Irene Pimentel (2001) têm evidenciado, porém, a forma como o regime permitiu o acesso a lugares de destaque de certos grupos (especialmente, os grupos católicos) e associações de mulheres (especialmente as associadas a valores familistas e caritativos).

5. O primeiro Grupo de Trabalho deu lugar, logo em 1971, ao Grupo de Trabalho para a Participação das Mulheres na Vida Económica e Social e, em 1973, à Comissão para a Política Social Relativa à Mulher.

6. O Graal é um movimento internacional de mulheres trazido para Portugal, em 1957, por Maria de Lourdes Pintasilgo e Teresa Santa Clara Gomes. Ver mais em $<$ http://www.graal.org.pt/graal.php?id=1>.

7. Para um desenvolvimento mais detalhado da análise do período marcelista ver o trabalho de Fernando Rosas e de Pedro A. Oliveira (2004).

8. Do primeiro grupo de técnicas convidadas por Maria de Lourdes Pintasilgo faziam parte: Aurora Fonseca, Maria Odete Esteves de Carvalho, Fernanda Agria, Maria do Carmo Romão, Bertina de Sousa Gomes. Mais tarde viriam também a integrá-lo Fátima Falcão Campos, Ana Maria Braga da Cruz e Regina Tavares da Silva.

9. Decisiva terá sido a relação próxima que viria a desenvolver com ele e sua esposa com quem, segundo relatos, era frequentemente convidada a ir tomar chá.

10. Referiam-se às afirmações de uma candidata a deputada do Partido Social Democrata (PSD) acerca da criação de um serviço da condição feminina, em relação às quais se viram obrigadas a vir a público clamar o óbvio, ou seja, que já existiam (Relatório de Atividades de 1976:33).

11. Convenção adotada pela OIT em 1951, relativa à Igualdade de Remuneração entre a Mão-de-obra Masculina e a Mão-de-obra Feminina em Trabalho de Valor Igual.

12. Tipo de resposta estatal em que o Estado permitiu que a Comissão participasse do processo de decisão e produção política e proporcionou resultados substantivos, ou seja, acolheu as suas propostas (Monteiro, 2011a). Os restantes tipos são Não resposta, cooptação, apropriação. 


\section{Feminismo de Estado Emergente na Transição Democrática em Portugal}

13. A OIT havia lançado na década de 1950 duas importantíssimas Convenções (a 100 e a 111), ratificadas por Portugal em 1969. A primeira, como já se indicou, sobre igualdade salarial, e a segunda sobre discriminação em matéria de emprego e trabalho.

14. Referência ao incidente provocado pela publicação, por três escritoras portuguesas (Maria Teresa Horta, Maria Isabel Barreno e Maria Velho da Costa), de uma obra que denunciava a situação de discriminação e opressão das mulheres portuguesas, bem como a questão colonial, e que foi proibida pelo regime. As suas autoras foram alvo de um processo judicial acusando o conteúdo erótico e imoral da obra, o que desencadeou algumas manifestações de solidariedade feminista no estrangeiro.

15. Quando o Estado não permite que a Comissão participe no processo de decisão política, mas integra conteúdos substantivos e produz legislação relevante para a igualdade de mulheres e homens (Monteiro, 2011a).

16. Cartas com propostas à Constituinte, aos partidos, ao Movimento das Forças Armadas.

17. Como Gunther (2002) refere, nos primeiros doze anos da sua história democrática Portugal apresentou um dos mais lamentáveis cadastros de instabilidade governamental da Europa.

18. Exemplo desta animosidade é o já tão referido episódio da Manifestação do MLM no Parque Eduardo VII e as reações e equívocos que tal episódio tem gerado (Barbosa, 1998). 


\section{REFERÊNCIAS BIBLIOGRÁFICAS}

AGUIAR, Joaquim. (1987), "Formas de Dominação e Sociedade: O Caso do Neo-patrimonialismo". Análise Social, vol. XXIII, no 96, pp. 241-278.

BARBOSA, Madalena. (1998), A Criação de um Mito. Comunicação apresentada no seminário Movimento Feminista em Portugal, Lisboa, UMAR, 5 e 6 de dezembro.

FERREIRA, Virgínia. (2011), “Engendering Portugal: Social Change, State Politics and Women's Social Mobilization", in A. C. Pinto (ed.), Contemporary Portugal. Boulder, Columbia University Press, pp. 153-192.

FERREIRA, José Medeiros. (1993), “Portugal em Transe (1974-1985)”, in J. Mattoso, (ed.), História de Portugal. Lisboa, Círculo de Leitores, pp. 7-11.

FRANCESCHET, Susan. (2003), “'State Feminism' and Women's Movements: The Impact of Chile's Servicio Nacional de la Mujer on Women's Activism". Latin American Research Review, vol. 38, no 1, pp. 9-40.

GORJÃO, Vanda. (2002), Mulheres em Tempos Sombrios: Oposição Feminina ao Estado Novo. Lisboa, Instituto de Ciências Sociais.

GUADAGNINI, Marila. (1995), “The Latecomers: Italy's Equal Status and Equal Opportunity Agencies", in D. M. McBride e A. Mazur (eds.), Comparative State Feminism. Thousand Oaks, Sage, pp. 150-167.

GUNTHER, Richard. (2002), "A Democracia Portuguesa em Perspectiva Comparada". Análise Social, vol. XXXVII, no 162, pp. 91-119.

HOLLI, Anne Maria. (2008), “Feminist Triangles: A Conceptual Analysis". Representation, vol. 44, no 2, pp. 169-185.

HTUN, Mala e WELDON, Laurel. (2007), When and Why do Governments Promote Women's Rights? Toward a Comparative Politics of States and Sex Equality. Comunicação apresentada na reunião annual da American Political Science Association. Chicago, 30 de agosto a 2 de setembro.

JALALI, Carlos. (2007), Partidos e Democracia em Portugal 1974-2005. Lisboa, Instituto de Ciências Sociais.

KARDAM, Nüket e ACUNER, Selma. (2003), National Women Machineries: Structures and Spaces. Mainstreaming Gender, Democratizing The State?", in S. Rai (ed.), Mainstreaming Gender, Democratizing The State? Institutional Mechanisms for the Advancement of Women. Manchester, Manchester University Press, pp. 96-113.

KECK, Margaret E. e SIKKINK, Kathryn. (1998), Activists beyond Borders: Transnational Advocacy Networks in International Politics. Ithaca, Cornell University Press.

LOVENDUSKI, Joni (2005), "Introduction: State Feminism and the Political Representation of Women", in J. Lovenduski, (ed.), State Feminism and Political Representation. Cambridge, Cambridge University Press, pp. 1-19.

MAZUR, Amy e MCBRIDE, Dorothy. (2010), The Politics of State Feminism: Innovation in Comparative Research. Philadelphia, Temple University Press. 
McADAM, Doug. (1998), “On the International Origins of Domestic Political Opportunities", in A. N. Costain e A. S. McFarland (eds.), Social Movements and American Political Institutions. Lanham, Rowman \& Littlefield, pp. 251-267.

McBRIDE, Dorothy e MAZUR, Amy G. (2008), “Women's Movements, Feminism, and Feminist Movements", in G. Goertz e A. Mazur (eds.), Politics, Gender, and Concepts: Theory and Methodology. Cambridge, Cambridge University Press, pp. 219-243.

(eds.). (1995), Comparative State Feminism. Thousand Oaks, Sage.

MELO, Daniel. (2007), “As Associações Públicas Voluntárias de Cariz Sociocultural em Portugal e as Políticas Públicas". Finisterra, nos 58/59/60, pp. 207-36.

MONTEIRO, Rosa. (2011a), Feminismo de Estado em Portugal: Mecanismos, Estratégias, Políticas e Metamorfoses. Tese de doutorado apresentada à FEUC/CES, Universidade de Coimbra.

. (2011b), "A Política de Quotas em Portugal: O Papel dos Partidos Políticos e do Feminismo de Estado". Revista Crítica de Ciências Sociais, vol. 92, pp. 31-50.

(2010a), A Emergência do Feminismo de Estado em Portugal: Uma História da Criação da Comissão da Condição Feminina. Lisboa, CIG.

(2010b), “Genealogia da Lei da Igualdade no Trabalho e no Emprego desde Finais do Estado Novo", in V. Ferreira (org.), A Igualdade de Mulheres e Homens no Trabalho e no Emprego em Portugal: Políticas e Circunstâncias. Lisboa, CITE, pp. 31-56.

PIMENTEL, Irene Flunser. (2001), As Organizações Femininas do Estado Novo. Lisboa, Temas \& Debates.

RÊGO, Maria do Céu da Cunha. (2010), “A Construção da Igualdade de Homens e Mulheres no Trabalho e no Emprego na Lei Portuguesa", in V. Ferreira (ed.), A Igualdade de Mulheres e Homens no Trabalho e no Emprego: Políticas e Circunstâncias. Lisboa, CITE, pp. 57-98.

SANTOS, Boaventura de Sousa. (1993), "O Estado, as Relações Salariais e o Bem-Estar Social na Semi-periferia: O Caso Português", in B. de S. Santos (org.), Portugal: Um Retrato Singular. Porto, Afrontamento, pp. 15-56.

(1984), "A Crise e a Reconstituição do Estado em Portugal (1974-1984)". Revista Crítica de Ciências Sociais, vol. 14, pp. 7-29.

SUBOTIC, Jelena. (2005), “Hijacked Justice: Domestic Appropriation of International Norms". Working Paper no 28, disponível em http:/ / www.du.edu/gsis/hrhw / working/2005/28-subotic-2005.pdf, acessado em 15/8/2008.

TARROW, Sidney. (1998), Power in Movement: Social Movements and Contentious Politics. Cambridge, Cambridge University Press.

TEIXEIRA, Conceição Pequito. (2009), O Povo Semi-Soberano. Partidos Políticos e Recrutamento Parlamentar em Portugal. Coimbra, Almedina.

VALIENTE, Celia. (1995), "The Power of Persuasión: The Instituto de la Mujer in Spain", in D. McBride e A. Mazur (eds.), Comparative State Feminism. Thousand Oaks, Sage.

WAYLEN, Georgina. (1998), "Gender, Feminism and the State: An Overview", in V. Randall e G. Waylen (eds.), Gender, Politics and the State. London, Routledge, pp. 1-17.

. (1997), “Women's Movements, the State and Democratization in Chile: The Establishment of SERNAM", in A. M. Goetz (ed.), Getting Institutions Right for Women in Development. London, Zed Books, pp. 90-103. 


\section{ABSTRACT \\ Emerging-State Feminism during the 1970s Democratic Transition in Portugal}

This study aimed to investigate and interpret the creation of a government mechanism for gender equality from 1970 to 1977 and to explore the key factors and players. The study drew analytically on contributions from the political process and state feminism approaches. The study questions the government mechanism's role in relation to equality, as a function of factors proposed in the literature, e.g., structures for political opportunities and mobilization, conceiving the political results as products of actions by (and interactions between) players in a specific context. A qualitative case study was prepared, focusing on document analysis and the analysis of 53 interviews with key players. The study concludes that the Portuguese political system allowed little room for integration of the gender equality policy agenda, even during the country's democratization process.

Key words: state feminism; Portugal; democratization; structures for political opportunities

\section{RÉSUMÉ}

L'Apparition du Féminisme d'État au Portugal Pendant la Transition Démocratique des Années 1970

Par cette recherche, on a voulu connaître et interpréter le processus de création des mécanismes officiels vers l' égalité entre 1970 et 1977 en en étudiant les facteurs déterminants. Dans cette analyse, on a pris en compte les contributions du processus politique et du féminisme d'État. On s'interroge sur le rôle des mécanismes officiels vers l'égalité compte tenu des facteurs proposés dans la littérature, tels que les structures d'opportunités politiques et de mobilisation en concevant les résultats politiques comme des produits d' (inter)actions d'agents dans un contexte donné. Une étude de cas qualitative à partir de documents et de l'analyse de 53 entretiens auprès d'agents importants, a été réalisée. Les résultats révèlent une ouverture réduite du système politique portugais concernant l'intégration du programme politique de l'égalité, même pendant la période de démocratisation du pays.

Mots-clés: féminisme d'État; Portugal; démocratisation; structures d'opportunités politiques 